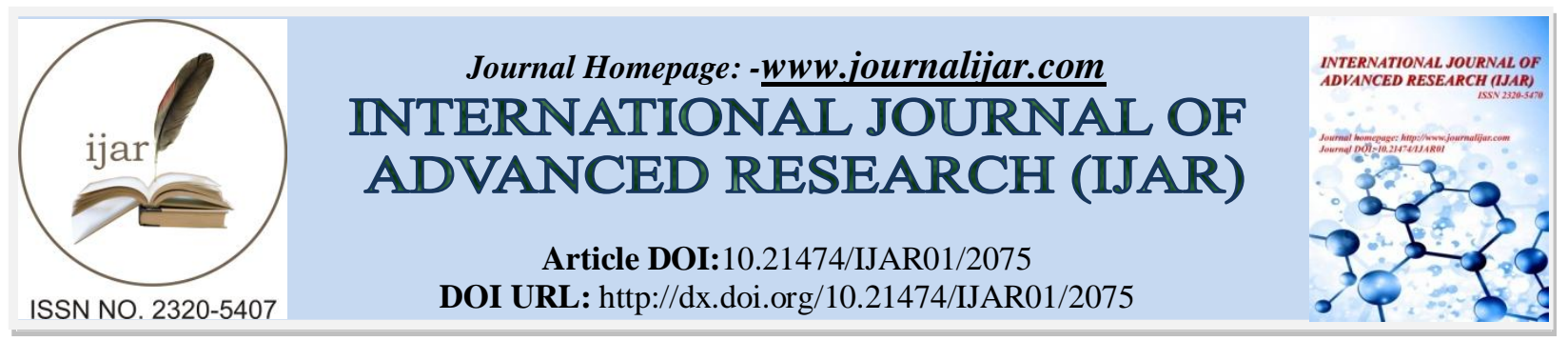

RESEARCH ARTICLE

\title{
ACCURACY EVALUATION OF GPS MONITORING TECHNIQUE OF HORIZONTAL AND VERTICAL STRUCTURAL DEFORMATIONS.
}

Zahraa Ezzulddin Hussein.

Assistant LecturerEngineering College-Baghdad University.

\section{Manuscript Info}

Manuscript History

Received: 24 September 2016

Final Accepted: 25 October 2016

Published: November 2016

Key words:-

GPS monitoring, deformation,

deflection, settlement.

\section{Abstract}

This research looks at the practical side to detect the possibility of using GPS technique in monitoring of horizontal and vertical structural deformations. This can be achieved by observing the deflection and the settlement of the building using static GPS technique. Then in this research, observations of GPS are evaluated by comparing with the observations of total station. Findings of this study show high accuracy of GPS to detect any relative movements reach to about $1 \mathrm{~mm}$ in horizontal side and $2 \mathrm{~mm}$ regarding the vertical side.

Copy Right, IJAR, 2016,. All rights reserved.

\section{Introduction:-}

Recently, monitoring systems of deformation play an important role to maintain the integrity of human in addition to preserving the economy of his achievements. Hence, providing the possibility of precise deformation monitoring is more requirements of the times for keeping up various industries, such as the monitoring of different engineering structures, structure buildings, and historical monuments, Im, et al.,2011. This technique is a necessary during construction stage of the building and after to avoid any damage may occur to the building with time. Generally, the object deformation can be defined as the difference of its position, shape and sizes regarding to its original site or its shape. Thus, the intent of observing deformations is not determination of the exact locations but the difference of these locations with time. There are different methods to achieve the monitoring of deformations depending on the level of required accuracy and the amount of the expected deformations in addition to its direction. In this study, monitoring by the static GPS technique is selected due to offering a time, cost and not need to inter-visibility between locations in the work, this on the contrary the conventional methods, Hudnut, and Behr, 1998; Celebi, 2000.

\section{Study area:-}

In this study, Al Khwarizmi college of engineering/ University of Baghdad was selected as the study areato investigate the accuracy of GPS technique for the monitoring of deformations. This study area located in the Jadriya neighborhood along the Tigris River in Baghdad, Iraq with Geographic coordinates $33^{\circ} 16^{\prime} 47.70^{\prime \prime}$ to the North and $44^{\circ} 23^{\prime} 06.44^{\prime \prime}$ to the East. Additionally, the dimensions of $\mathrm{Al}$ Khwarizmi structure are approximately $83 \mathrm{~m}$ in the North-South direction and 70m in the East-West directionsas illustrated in Fig.1.

Corresponding Author:-Zahraa Ezzulddin Hussein.

Address:-Assistant LecturerEngineering College-Baghdad University. 


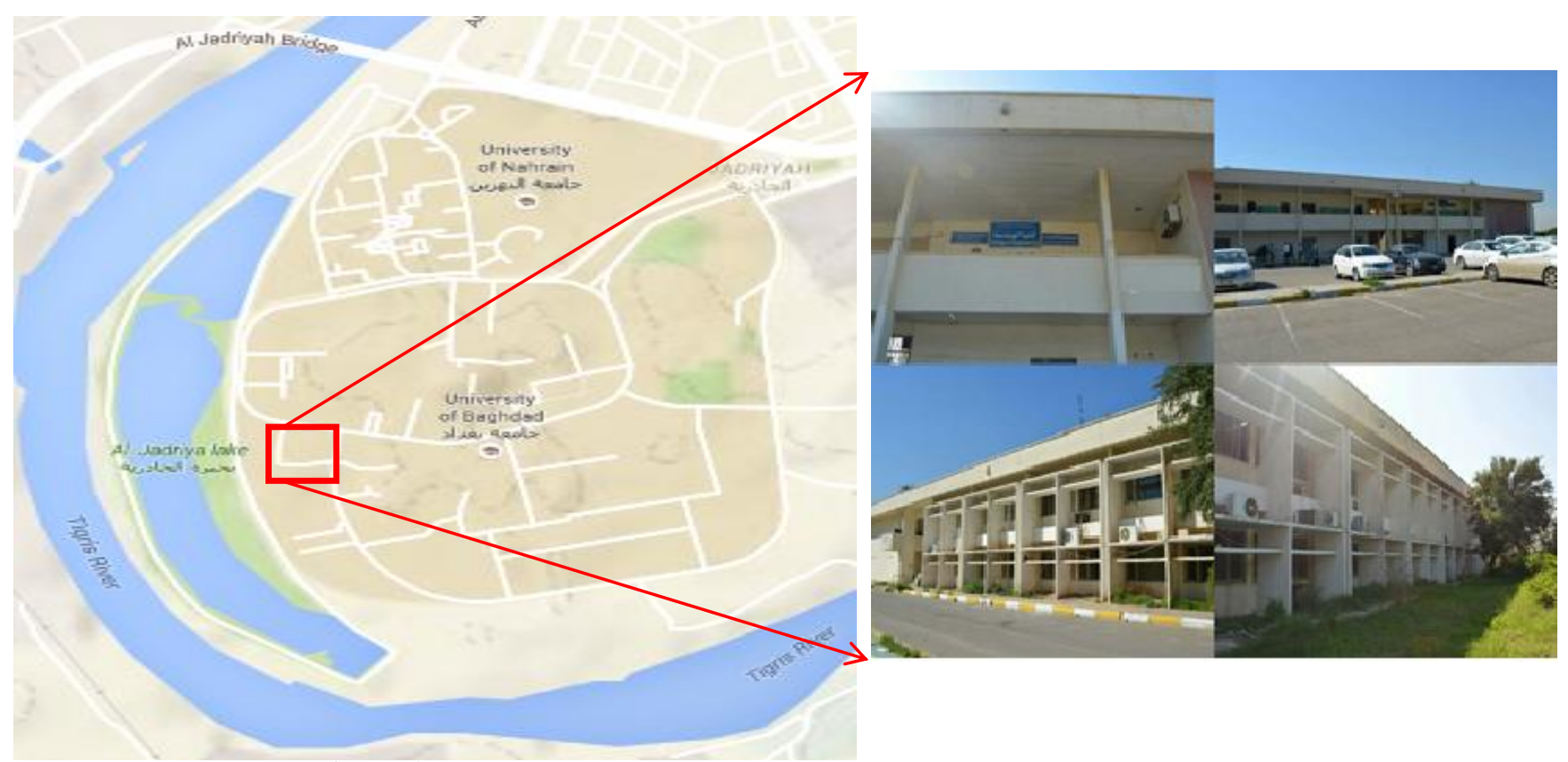

Figure 1:- 2D map of Al Khwarizmi college case study (Google ()).

\section{Methodology:-}

The methodology of this study consists of several experimental works which can be summarized as following:

\section{Initial accuracy evaluation of horizontal and vertical GPS observations:-}

In the case of horizontal accuracy evaluation, itis determined a line on the ground with length of one meter which was divided into four equal parts in the length of each twenty-five centimeter as showing Fig.2-a.Firstly, the whole line and its four parts were measured using a metallic tape. Then, the same line and its parts were measured by static GPS technique with period of 25 minute at each station. On the other hand, it is determined a block with height of one meter in the case of vertical accuracy evaluation as shown in Fig.2-b. Like the first case, the block was divided into four equal parts and then measuring their related heights by metallic tape and GPS technique respectively for evaluation purpose.

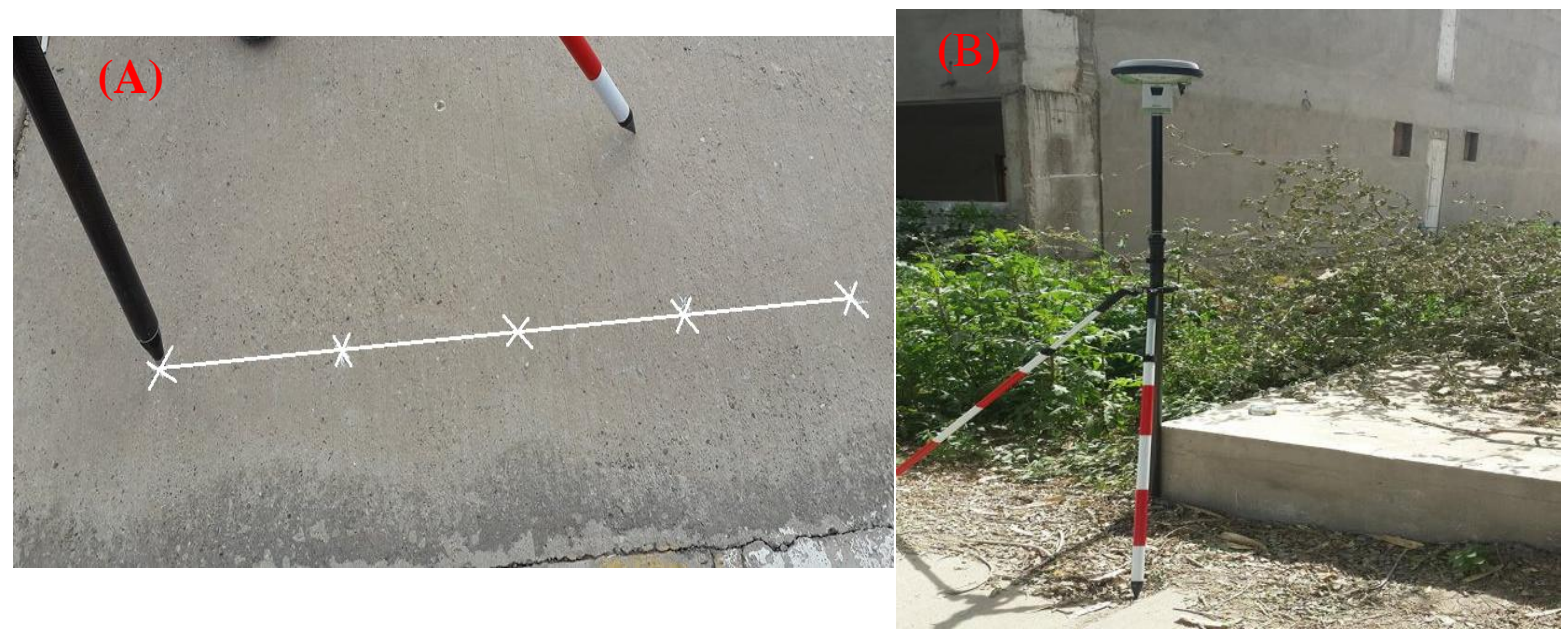

Figure 2:- (A)Horizontal accuracy evaluation, (B) Vertical accuracy evaluation

\section{Measurements of study structure using static GPS technique:-}

Two GPS receivers which are of model Leica Viva are used in this case. One of GPS receivers is fixed on control points and the other is moved to observe specific points of the structure with period of 25 minute. The four interfaces of the structure were divided to a number of columns and then measure the bottom points and related 
vertex points to computethe horizontal and the vertical movements. The horizontal movements can be computed based on the differences between the bottom points and the corresponding top points of structure as following,Ebeling, 2014; Hussein, 2016:-

$\tan \emptyset=\frac{\Delta y}{\Delta x} \quad(1)$

where $\varnothing$ is the angle of horizontal movements, and $\Delta y, \Delta x$ are the coordinates differences between the bottom point and the top point of structure on the same line. Additionally, the horizontal difference movement can be determined as, Abdel-Gawad, et al., 2014; Hudnut, et al.,2001:

$d=\sqrt{\Delta x^{2}+\Delta y^{2}}(2)$

where, $\boldsymbol{d}$ refers to the slope distance movement in millimeters.

On other hand, the vertical movements can be computed as following, Kaloop, and Li, 2009; Ibrahim, et al., 2010: $\Delta z_{12}=z_{2}-z_{1}(3)$

Where, $\Delta \boldsymbol{z}_{\mathbf{1 2}}$ stands to elevation difference between two points located on two adjacent columnswith the same row of the top structure, and zrefers to the elevation of the top points of the structure, which located on one of the columns that divided the structure.

Thus, the horizontal and vertical movements may be explained in Fig.3.

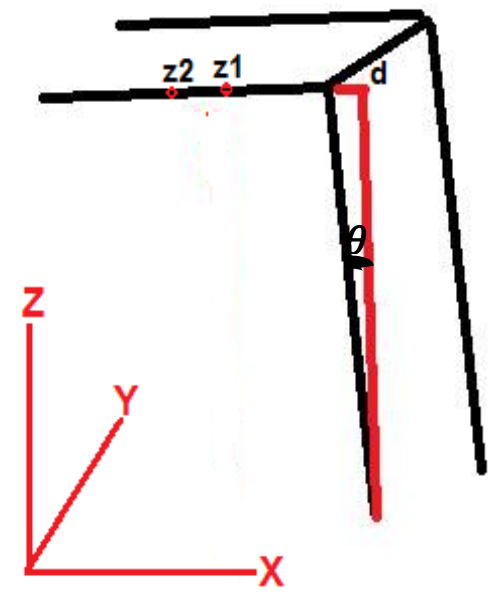

Figure 3:- An explanatory sketch for the horizontal and vertical movements.

\section{Measurements of study structure using total station technique:-}

Like the GPS technique, the horizontal and the vertical movements were observed by total station and compared their results with GPS technique. the same bottom and top points of divided columns, which observed by GPS technique, were observed by the total station to compute the difference between them. thus in this study, the results of total station were considered as a reference to evaluate the accuracy of GPS technique.

\section{Results and Discussions:-}

Regarding the horizontal accuracy evaluation, the differences in the measured line, which explained in the step of initial accuracy evaluation of the study methodology, between the metallic tape and the GPS technique were summarized in Table 1.

Table 1:- Summary of observations regarding the selected horizontal distance.

\begin{tabular}{|l|l|l|l|l|}
\hline From & To & Metallic tape distance $(\mathbf{m})$ & GPS horizontal distance $(\mathbf{m})$ & Error $(\mathbf{m})$ \\
\hline 1 & 2 & 0.25 & 0.253 & 0.003 \\
\hline 2 & 3 & 0.25 & 0.254 & 0.004 \\
\hline 3 & 4 & 0.25 & 0.253 & 0.003 \\
\hline 1 & 4 & 1.00 & 1.006 & 0.006 \\
\hline
\end{tabular}


On the other hand, the elevation differences regarding the vertical accuracy evaluation were explained in Table 2.

Table 2:- Summary of observations regarding the selected vertical distance.

\begin{tabular}{|l|l|l|l|l|}
\hline From & To & Metallic tape distance $(\mathbf{m})$ & GPS vertical distance $(\mathbf{m})$ & Error $(\mathbf{m})$ \\
\hline 1 & 2 & 0.25 & 0.261 & 0.011 \\
\hline 2 & 3 & 0.25 & 0.259 & 0.009 \\
\hline 3 & 4 & 0.25 & 0.260 & 0.010 \\
\hline 1 & 4 & 1.00 & 1.015 & 0.015 \\
\hline
\end{tabular}

From the previous tables, it can be noted the maximum difference regarding the horizontal observations is not exceed one centimeters contrary to the vertical accuracy that exceeded it, this explains the realism GPS accuracythat have the horizontal accuracy twice than the vertical accuracy. Later in terms of GPS measurements of the study structure mentioned in the research methodology, the horizontal differences between the top and the bottom points of the same column in addition to vertical difference between adjacent columns are calculated, after dividing the building into a 163 column using GPS technique as explain in Table3that contains arbitrary sample of the total measurements.Like method of the previous measurements using GPS technique, the horizontal and vertical differences were measured for the same number of points (163 points) using total station device.

Table 3:- GPS computations showed the horizontal and vertical differences for arbitrary sample of points.

\begin{tabular}{|l|l|l|l|l|l|}
\hline \multirow{2}{*}{ Points } & \multicolumn{2}{|l|}{ Coordinate differences $(\mathrm{m})$} & $\begin{array}{l}\text { Horizontal difference }(\mathrm{d} \text { in } \\
\text { meter })\end{array}$ & $\begin{array}{l}\text { Vertical difference }(\mathrm{z} \text { in } \\
\text { meter })\end{array}$ \\
\cline { 2 - 6 } & $\mathrm{Dx}$ & $\mathrm{Dy}$ & $\mathrm{Dz}$ & 0.007 & 0.009 \\
\hline 1 & -0.005 & -0.005 & 4.085 & 0.005 & 0.008 \\
\hline 2 & -0.004 & -0.003 & 4.076 & 0.005 & 0.012 \\
\hline 3 & 0.003 & -0.004 & 4.084 & 0.006 & 0.016 \\
\hline 5 & 0.002 & -0.006 & 4.072 & -0.051 & 0.029 \\
\hline 6 & 0.051 & -0.006 & 4.056 & 0.051 & 0.009 \\
\hline 7 & -0.004 & -0.005 & 4.085 & 0.006 & 0.008 \\
\hline 8 & -0.002 & -0.003 & 4.076 & 0.003 & 0.011 \\
\hline 9 & 0.001 & -0.005 & 4.084 & 0.005 & 0.018 \\
\hline 10 & 0.002 & -0.005 & 4.073 & 0.005 & 0.030 \\
\hline 11 & 0.060 & -0.003 & 4.055 & 0.060 & 0.009 \\
\hline 12 & -0.005 & -0.004 & 4.085 & 0.006 & 0.009 \\
\hline 13 & -0.004 & -0.006 & 4.076 & 0.007 & 0.013 \\
\hline 14 & 0.003 & -0.006 & 4.085 & 0.006 & 0.017 \\
\hline 15 & 0.002 & -0.005 & 4.072 & 0.005 & 0.030 \\
\hline 16 & 0.060 & -0.003 & 4.055 & 0.060 & 0.008 \\
\hline 17 & -0.005 & -0.005 & 4.085 & 0.007 & 0.007 \\
\hline 18 & -0.004 & -0.003 & 4.077 & 0.005 & 0.012 \\
\hline 19 & 0.003 & -0.004 & 4.084 & 0.005 & 0.017 \\
\hline 20 & 0.002 & -0.006 & 4.072 & 0.006 & 0.030 \\
\hline 21 & 0.060 & -0.006 & 4.055 & 0.060 & 0.009 \\
\hline 22 & -0.005 & -0.005 & 4.085 & 0.007 & 0.008 \\
\hline 23 & 0.004 & -0.003 & 4.076 & 0.005 & 0.012 \\
\hline 24 & 0.002 & -0.005 & 4.084 & 0.005 & 0.016 \\
\hline 25 & 0.060 & -0.005 & 4.072 & 0.005 & 0.029 \\
\hline 26 & -0.005 & -0.004 & 4.056 & 0.060 & 0.009 \\
\hline 27 & -0.004 & -0.006 & 4.076 & 0.006 & 0.008 \\
\hline 28 & 0.003 & -0.006 & 4.084 & 0.006 & 0.011 \\
\hline 29 & 0.002 & -0.005 & 4.073 & 0.005 & 0.018 \\
\hline 30 & 0.060 & -0.003 & 4.055 & 0.060 & 0.009 \\
\hline 31 & -0.005 & -0.005 & 4.085 & 0.007 & 0.013 \\
\hline 32 & -0.004 & -0.003 & 4.076 & 0.005 & \\
\hline 33 & 0.003 & -0.004 & 4.085 & 0.005 & \\
\hline & & & & & \\
\hline
\end{tabular}




\begin{tabular}{|c|c|c|c|c|c|}
\hline 34 & 0.002 & -0.006 & 4.072 & 0.006 & 0.017 \\
\hline 35 & 0.060 & -0.006 & 4.055 & 0.060 & 0.030 \\
\hline 36 & -0.005 & -0.005 & 4.085 & 0.007 & 0.008 \\
\hline 37 & -0.004 & -0.003 & 4.077 & 0.005 & 0.007 \\
\hline 38 & 0.003 & -0.005 & 4.084 & 0.005 & 0.012 \\
\hline 39 & 0.060 & -0.005 & 4.072 & 0.060 & 0.017 \\
\hline 40 & -0.005 & -0.003 & 4.055 & 0.005 & 0.030 \\
\hline 41 & -0.004 & -0.004 & 4.085 & 0.005 & 0.009 \\
\hline 42 & 0.003 & -0.006 & 4.076 & 0.006 & 0.008 \\
\hline 43 & 0.060 & -0.006 & 4.084 & 0.060 & 0.012 \\
\hline 44 & -0.005 & -0.005 & 4.072 & 0.007 & 0.016 \\
\hline 45 & -0.004 & -0.003 & 4.056 & 0.005 & 0.029 \\
\hline 46 & 0.003 & -0.005 & 4.085 & 0.005 & 0.009 \\
\hline 47 & 0.060 & -0.003 & 4.076 & 0.060 & 0.008 \\
\hline 48 & -0.005 & -0.004 & 4.084 & 0.006 & 0.011 \\
\hline 49 & -0.004 & -0.006 & 4.073 & 0.007 & 0.012 \\
\hline 50 & 0.003 & -0.006 & 4.085 & 0.006 & 0.009 \\
\hline 51 & 0.060 & -0.005 & 4.076 & 0.060 & 0.008 \\
\hline 52 & -0.005 & -0.003 & 4.084 & 0.005 & 0.011 \\
\hline 53 & -0.004 & -0.005 & 4.073 & 0.006 & 0.018 \\
\hline 54 & 0.003 & -0.005 & 4.055 & 0.005 & 0.030 \\
\hline 55 & 0.060 & -0.003 & 4.085 & 0.060 & 0.009 \\
\hline 56 & -0.005 & -0.004 & 4.076 & 0.006 & 0.009 \\
\hline 57 & -0.004 & -0.006 & 4.085 & 0.007 & 0.013 \\
\hline 58 & 0.003 & -0.006 & 4.072 & 0.006 & 0.017 \\
\hline 59 & 0.060 & -0.005 & 4.055 & 0.060 & 0.030 \\
\hline 60 & -0.005 & -0.003 & 4.085 & 0.005 & 0.008 \\
\hline 61 & -0.004 & -0.005 & 4.077 & 0.006 & 0.007 \\
\hline 62 & 0.003 & -0.003 & 4.084 & 0.004 & 0.001 \\
\hline 63 & 0.060 & -0.004 & 4.085 & 0.060 & 0.009 \\
\hline 64 & -0.005 & -0.006 & 4.076 & 0.007 & 0.009 \\
\hline 65 & -0.004 & -0.006 & 4.085 & 0.007 & 0.013 \\
\hline 66 & 0.003 & -0.005 & 4.072 & 0.005 & 0.017 \\
\hline 67 & 0.060 & -0.003 & 4.055 & 0.060 & 0.030 \\
\hline 68 & -0.005 & -0.005 & 4.085 & 0.007 & 0.008 \\
\hline 69 & -0.004 & -0.005 & 4.077 & 0.006 & 0.007 \\
\hline 70 & 0.003 & -0.003 & 4.084 & 0.004 & 0.012 \\
\hline 71 & 0.060 & -0.004 & 4.072 & 0.060 & 0.012 \\
\hline 72 & -0.005 & -0.006 & 4.084 & 0.007 & 0.001 \\
\hline 73 & -0.004 & -0.006 & 4.085 & 0.007 & 0.009 \\
\hline 74 & 0.003 & -0.005 & 4.076 & 0.005 & 0.008 \\
\hline
\end{tabular}

Regarding Table 3, the root mean square errors (RMSEs), which computed for the horizontal and vertical differences, are $0.0298 \mathrm{~m}$ and $0.0147 \mathrm{~m}$ respectively. Additionally, all these differences can be explained in Fig.4. 


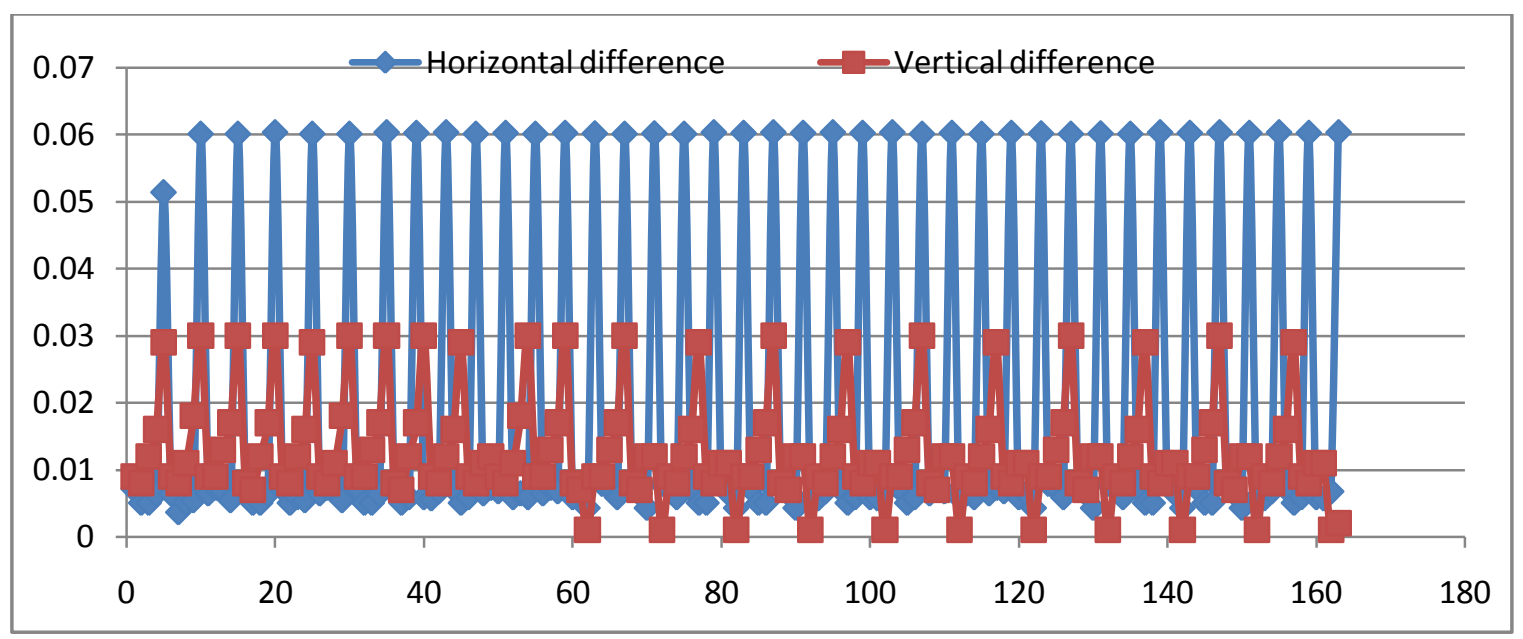

Figure 4:- An explanatory diagram for the horizontal and vertical differences.

On other hand, the same sample of the GPS measurements can be used to illustrate the differences that observed by the total station device as listed in Table 4.

Table 4:- Computations of total station device showed the horizontal and vertical differences for arbitrary sample of points.

\begin{tabular}{|c|c|c|}
\hline Points & Horizontal difference ( $\mathrm{d}$ in meter) & Vertical difference ( $\mathrm{z}$ in meter) \\
\hline 1 & 0.009 & 0.010 \\
\hline 2 & 0.006 & 0.009 \\
\hline 3 & 0.005 & 0.012 \\
\hline 4 & 0.008 & 0.019 \\
\hline 5 & 0.054 & 0.030 \\
\hline 6 & 0.009 & 0.010 \\
\hline 7 & 0.004 & 0.010 \\
\hline 8 & 0.005 & 0.012 \\
\hline 9 & 0.007 & 0.021 \\
\hline 10 & 0.062 & 0.032 \\
\hline 11 & 0.008 & 0.009 \\
\hline 12 & 0.008 & 0.012 \\
\hline 13 & 0.010 & 0.013 \\
\hline 14 & 0.005 & 0.018 \\
\hline 15 & 0.060 & 0.031 \\
\hline 16 & 0.007 & 0.010 \\
\hline 17 & 0.005 & 0.007 \\
\hline 18 & 0.007 & 0.014 \\
\hline 19 & 0.008 & 0.017 \\
\hline 20 & 0.060 & 0.030 \\
\hline 21 & 0.010 & 0.012 \\
\hline 22 & 0.007 & 0.009 \\
\hline 23 & 0.008 & 0.015 \\
\hline 24 & 0.005 & 0.020 \\
\hline 25 & 0.063 & 0.031 \\
\hline 26 & 0.010 & 0.012 \\
\hline 27 & 0.011 & 0.011 \\
\hline 28 & 0.010 & 0.013 \\
\hline 29 & 0.008 & 0.021 \\
\hline
\end{tabular}




\begin{tabular}{|c|c|c|}
\hline 30 & 0.062 & 0.030 \\
\hline 31 & 0.007 & 0.013 \\
\hline 32 & 0.006 & 0.009 \\
\hline 33 & 0.005 & 0.014 \\
\hline 34 & 0.006 & 0.021 \\
\hline 35 & 0.064 & 0.032 \\
\hline 36 & 0.008 & 0.011 \\
\hline 37 & 0.006 & 0.009 \\
\hline 38 & 0.007 & 0.013 \\
\hline 39 & 0.062 & 0.017 \\
\hline 40 & 0.008 & 0.033 \\
\hline 41 & 0.005 & 0.011 \\
\hline 42 & 0.010 & 0.010 \\
\hline 43 & 0.062 & 0.015 \\
\hline 44 & 0.010 & 0.016 \\
\hline 45 & 0.006 & 0.030 \\
\hline 46 & 0.007 & 0.012 \\
\hline 47 & 0.060 & 0.011 \\
\hline 48 & 0.007 & 0.011 \\
\hline 49 & 0.009 & 0.012 \\
\hline 50 & 0.008 & 0.009 \\
\hline 51 & 0.063 & 0.008 \\
\hline 52 & 0.006 & 0.013 \\
\hline 53 & 0.010 & 0.021 \\
\hline 54 & 0.008 & 0.033 \\
\hline 55 & 0.062 & 0.011 \\
\hline 56 & 0.010 & 0.009 \\
\hline 57 & 0.008 & 0.016 \\
\hline 58 & 0.008 & 0.017 \\
\hline 59 & 0.062 & 0.030 \\
\hline 60 & 0.008 & 0.008 \\
\hline 61 & 0.009 & 0.007 \\
\hline 62 & 0.004 & 0.001 \\
\hline 63 & 0.060 & 0.010 \\
\hline 64 & 0.009 & 0.010 \\
\hline 65 & 0.007 & 0.014 \\
\hline 66 & 0.007 & 0.018 \\
\hline 67 & 0.061 & 0.031 \\
\hline 68 & 0.007 & 0.012 \\
\hline 69 & 0.007 & 0.010 \\
\hline 70 & 0.007 & 0.014 \\
\hline 71 & 0.062 & 0.012 \\
\hline 72 & 0.009 & 0.002 \\
\hline 73 & 0.010 & 0.009 \\
\hline 74 & 0.006 & 0.012 \\
\hline
\end{tabular}

Like the previous step, the RMSEs were computed regarding the horizontal and the vertical distance in Table 4 and found equal to $0.0312 \mathrm{~m}$ and $0.0167 \mathrm{~m}$ respectively. Moreover, the difference values between the measurements of GPS and the measurements of total station were computed relative to the values of RMSE for the two techniques, these differences equal to $0.001 \mathrm{~m}$ in horizontal direction and $0.002 \mathrm{~m}$ in vertical direction. Thus, the accuracy of GPS not exceed two millimeterto detect the deformation values based on the measurements of total station, which is considered as a reference in this study.It is worth to mention that the all difference of measurements between GPS and total station device can be summarized in Fig.5. 


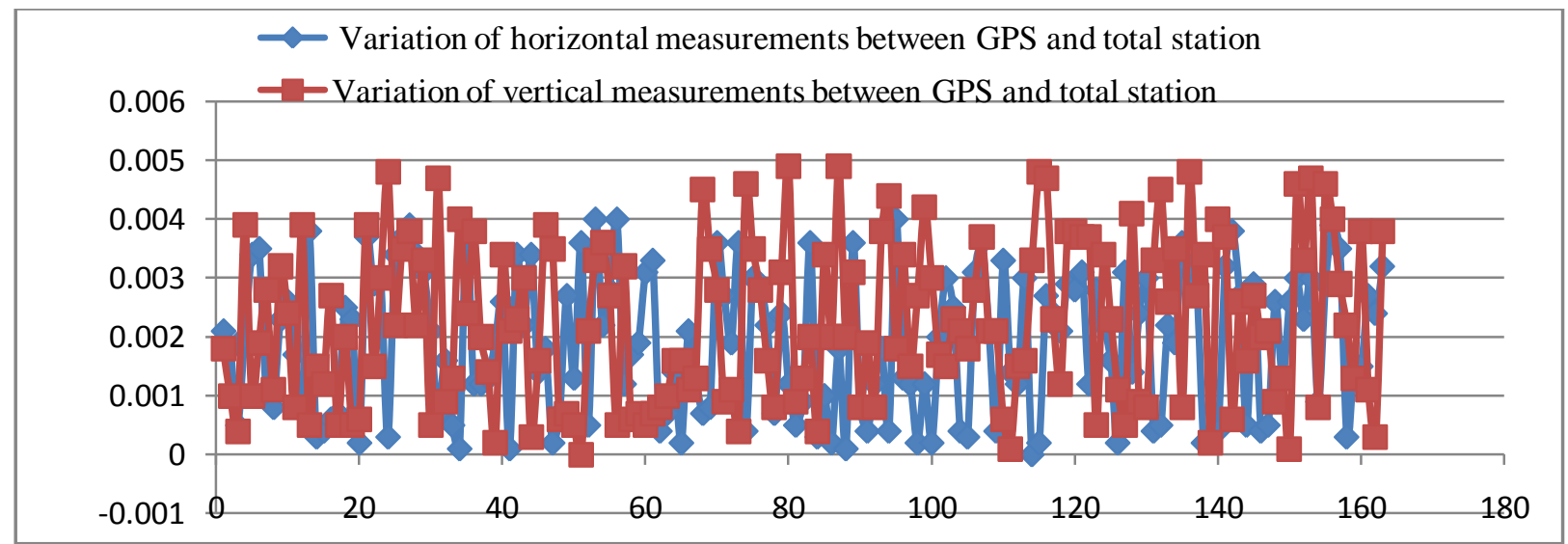

Figure 5:- An interpretive graph for the variation of measurements between GPS and total station device.

\section{Conclusion:-}

This study shows the mechanism to measure structural deformations using GPS technique and compare its result with precise traditional technique such as measuring by total station device. Regarding GPS technique, an average of the horizontal movements of the study structure was computed that reach to about $3.0 \mathrm{~cm}$. Additionally, the average of the vertical movements reach to about $1.4 \mathrm{~cm}$. Thus, the measurements of total station device gave results close to the findings of GPS technique with root mean square error equal to about $1 \mathrm{~mm}$ in horizontal direction and $2 \mathrm{~mm}$ in vertical direction.

\section{References:-}

1. Abdel-Gawad, A. K., Mogahed, Y. M., Mageed, K. M. A., and El-Maghraby, E. A., 2014, Evaluation and accuracy assessment of static GPS technique in monitoring of horizontal structural deformations, International OPEN ACCESS Journal Of Modern Engineering Research (IJMER), Vol.4, No.6.

2. Celebi, M., 2000, GPS in dynamic monitoring of long-period structures, Soil Dynamics and Earthquake Engineering, Vol.20, No.5, PP.477-483.

3. Ebeling, A., 2014,.Ground-based deformation monitoring, Doctoral dissertation, University of Calgary.

4. Hudnut, K.W., and Behr, J. A., 1998, Continuous GPS monitoring of structural deformation at Pacoima dam, California, Seismological Research Letters, a journal published by the Seismological Society of America, Vol. 69, No. 4, PP. 299-308.

5. Hudnut, K. W., Bock, Y., Galetzka, J. E., Webb, F. H., and Young, W. H., 2001, The southern California integrated GPS network (SCIGN), In The 10th FIG International Symposium on Deformation Measurements (pp. 19-22), Orange California, USA.

6. Hussein, Z.E., 2016, Accuracy evaluation of digital elevation model created using handheld

7. Global Positioning System receivers, Journal of Engineering, Vol.22, No.6, PP.137-148.

8. Ibrahim, M. R., Jaafar, J., Yahya, Z., and Samad, A. M., 2010, A feasibility study of building structural deformation monitoring using Global Positioning System (GPS), terrestrial surveying technique (TST) and crack gauge measurement (CGM)," Signal Processing and Its Applications (CSPA), 2010 6th International Colloquium on, Mallaca City, 2010, pp. 8-8.

9. Im, S. B., Hurlebaus, S., and Kang, Y. J., 2011, Summary review of GPS technology for structural health monitoring, Journal of Structural Engineering, Vol.139, No.10, PP.1653-1664.

10. Kaloop, M.R., and Li, H., 2009, Monitoring of bridge deformation using GPS technique, KSCE Journal of Civil Engineering, Vol.13, No.6, PP.423-431. 